\title{
Additive Color Mixing of Semi-Transparent Laminated Tandem Type Polymer Light-Emitting Diodes
}

Masahiro Morimotoa*, Yuya Ozawa ${ }^{\mathrm{b}}$, Shigeki Naka ${ }^{\mathrm{a}}$, and Hiroyuki Okada ${ }^{a}$ Academic Assembly Faculty of Engineering, University of Toyama, Gofuku, Toyama, 930-8555, Japan.

${ }^{b}$ Graduate School of Science and Engineering for Education, University of Toyama, Gofuku, Toyama, 930-8555, Japan.

*E-mail: morimoto@eng.u-toyama.ac.jp

\section{ORCID}

Masahiro Morimoto; 0000-0002-1156-6494 


\title{
Additive Color Mixing of Semi-Transparent Laminated Tandem Type Polymer Light-Emitting Diodes
}

\author{
Polymer light-emitting diodes (PLEDs) are generally fabricated using the wet \\ process. Although it is difficult to stack multiple layers by the wet process, it is \\ compatible with the lamination process that can be used to fabricate multi-layer \\ tandem type devices. We fabricate tandem type PLEDs composed of two \\ transparent substrates using the lamination process. Stacked red and green PLEDs \\ exhibit additive color mixed emission resulting in orange emission. By careful \\ selection of materials, similar emission is observed from both substrates of the \\ semi-transparent tandem PLEDs because the over-layer does not absorb the \\ emission from the under-layer.
}

Keywords: polymer light-emitting diode; lamination process; transparent devices

\section{Introduction}

Organic light-emitting diodes (OLEDs) have been widely used for television displays, illumination, and smartphone displays. OLEDs employ several molecular emission materials such as small molecule fluorescent $[1,2]$, phosphorescent $[3,4]$, thermally activated delayed fluorescent [5-7], and polymer [8-11] materials. Polymer lightemitting diodes (PLEDs) are generally coated using the wet process because polymer materials cannot be coated by vacuum deposition. The wet process, i.e., solutionprocess, has attracted considerable interest owing to its flexibility [12,13], large-area mass production compatibility, low-cost, and time-saving fabrication characteristics. Specific methods include spin-coating, dip-coating, blade-coating, and the newer inkjet printing. Despite significant progress, the wet process still has some challenges at the fabrication stage, such as the difficult to fabricate multi-layered films, dissolution of the under-layer, and poor surface morphology [14-16]. This is because almost all organic 
semiconductors are highly soluble in similar solvents; thus, multi-layered and tandem structures are challenging for PLEDs.

We have been focusing on the lamination process [17-21], which is wet process compatible, for PLED fabrication. The laminated PLEDs are formed by laminating two substrates. The semiconductor layers are coated on both the substrates; thus, the number of stacking operations can be reduced. This reduces the probability of dissolution of the under-layer and residual heating due to forming each respective layer. Furthermore, the lamination process is well-suited to tandem type devices requiring a large number of stacked layers [22,23], and can lead to reduced process times and transparent devices composed of two indium-tin-oxide (ITO) electrode substrates.

In this study, tandem type PLEDs are fabricated using the lamination process. All semiconductor layers are spin-coated onto ITO electrode substrates. Two different emission polymers are coated onto the anode and cathode electrode substrates, respectively, and the two substrates are laminated. The resulting tandem PLEDs exhibit two emission bands, thereby achieving additive color mixed emission. The semitransparent properties are evaluated by characterizing the emission spectra from both the anode and cathode of the tandem PLEDs.

\section{Experimental methods}

ITO coated glass substrates were treated by ultrasonication and UV/ozone before film coating. The electron injection layers used in this study were polyethylenimine ethoxylated (PEIE; Sigma Aldrich) and polyethylenimine (PEI; Sigma Aldrich), which were dissolved in 3-4 wt \% ethanol. The PEIE or PEI solution was spin-coated at 3000 rpm for $60 \mathrm{~s}$ onto the cathode side ITO substrates. The PEIE and PEI thicknesses were controlled to be under a few nanometers by the rinse method. Subsequently,

poly(ethylenedioxythiophene)/poly(styrenesulfonate) (PEDOT:PSS; H.C. Starck) was 


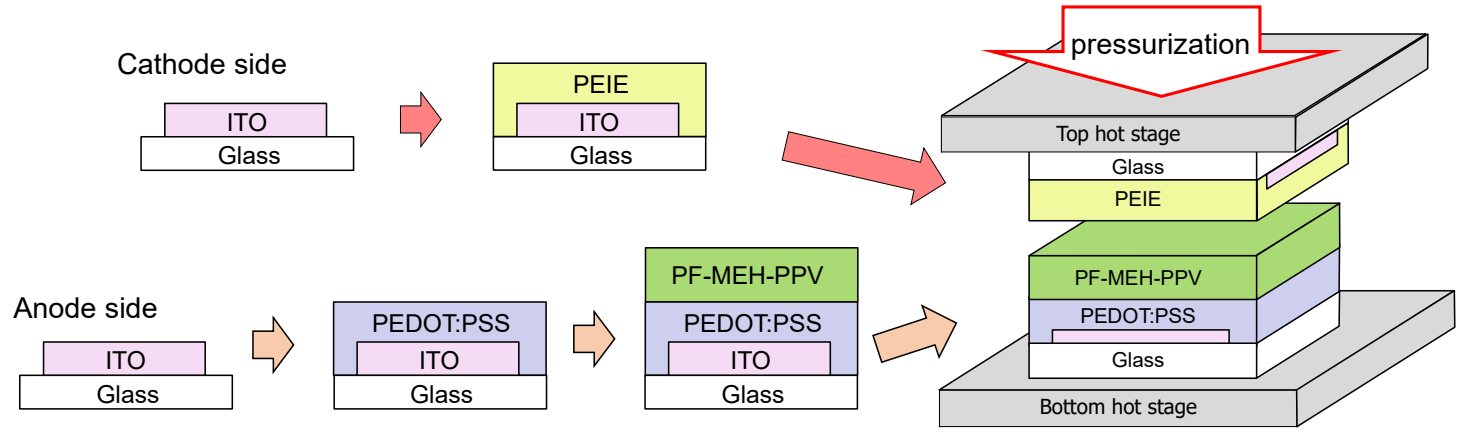

Figure 1. Schematic of lamination process for the single PLED with PF-MEH-PPV.

spin-coated at $3000 \mathrm{rpm}$ for $60 \mathrm{~s}$ onto the anode side ITO substrates as the hole injection layer and baked at $200^{\circ} \mathrm{C}$ for $5 \mathrm{~min}$ in air. Poly[(9,9-dioctyl-2,7-

divinylenefluorenylene)alt-\{2-methoxy-5-(2-ethylhexyloxy)-1,4-phenylene $\}]$ (PFMEH-PPV; Lumitec, Mw: 20,000) and RP145 (Sumitomo Chemical) as the emission layers were dissolved in $1.0 \mathrm{wt} \%$ tetrahydrofuran and p-xylene, respectively. Each solvent was spin-coated onto the PEDOT:PSS layer at $3000 \mathrm{rpm}$ for $60 \mathrm{~s}$ and baked at $150-210^{\circ} \mathrm{C}$ for $20 \mathrm{~min}$. Both ITO substrates were laminated using a heater press system (Mikado Technos, MKP-150PV-WH). The lamination pressure was $0.5 \mathrm{MPa}$ under vacuum at $150-210^{\circ} \mathrm{C}$ for $900 \mathrm{~s}$. The fabrication process for the laminated PLED is shown in Figure 1. Single PLEDs consisted of two electrodes for one emission layer; however, tandem PLEDs only had two electrodes for two emission layers. The tandem PLED requires a charge generation layer (CGL) between the two single PLEDs. The CGL used in this study was $\mathrm{MoO}_{3}$ (Kojundo Chemical Lab.), which was dissolved in $0.05 \mathrm{wt} \%$ mixed solvent consisting of $20 \%$ isopropyl alcohol and $80 \%$ deionized water. $\mathrm{ZnO}$ nanoparticles (Sigma Aldrich) were dissolved in $0.01 \mathrm{wt} \%$ isopropyl alcohol as the electron injection layer from the CGL to the emission layer. $\mathrm{MoO}_{3}$ and $\mathrm{ZnO}$ nanoparticles were spin-coated at $3000 \mathrm{rpm}$ for $60 \mathrm{~s}$ onto each emission layer and baked at $150^{\circ} \mathrm{C}$ for $20 \mathrm{~min}$. Figure 2 shows the appearance of various laminated PLEDs. The PF-MEH-PPV single PLED (Fig. 2a) composed of the green and colorless transparent 
(a)

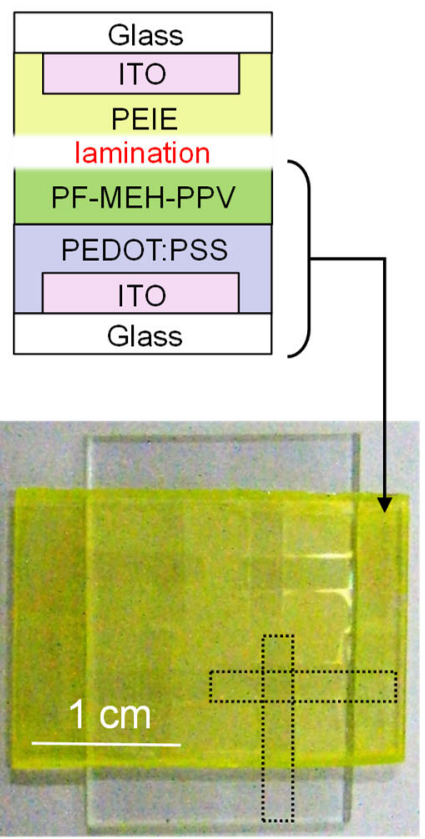

(b)

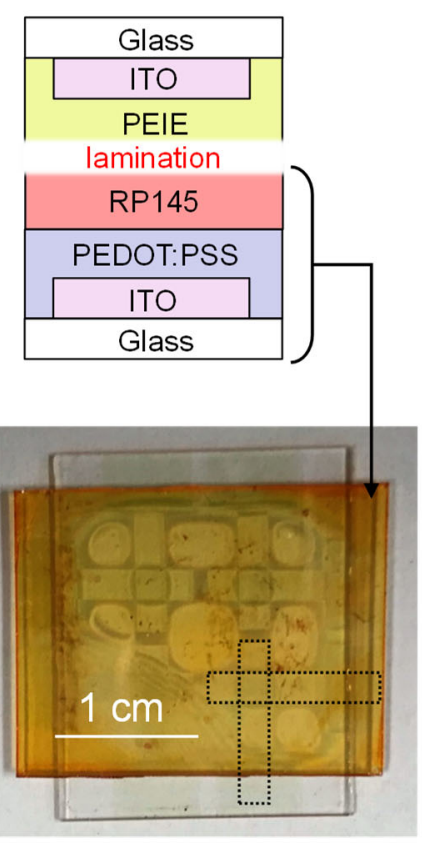

(c)
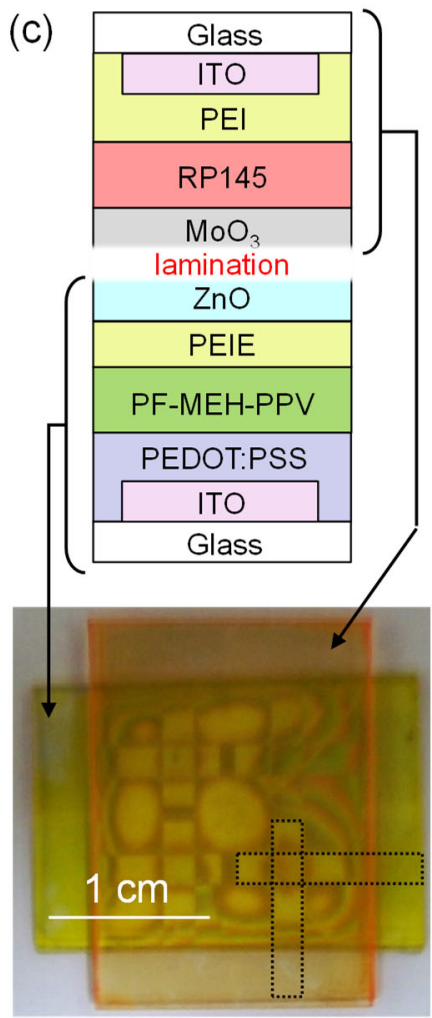

Figure 2. Device structure and appearance images of (a) single PLED with PF-MEHPPV, (b) single PLED with RP145, and (c) tandem PLED.

substrates, the RP145 single PLED composed of the orange and colorless transparent substrates, and the tandem PLED composed of the green due to PF-MEH-PPV and the orange due to RP145 substrates. Each pair of laminated substrates consists of four devices with an active area of $2 \times 2 \mathrm{~mm}$. The dotted lines in Figure 2 indicate the ITO electrode areas. All devices are semi-transparent; thus, semi-transparent PLEDs could be fabricated by the lamination process.

The PLED characteristics were evaluated based on the current density-applied voltage $(J-V)$ curve and the luminance-current density $(L-J)$ curve measured using a semiconductor parameter analyzer (Hewlett Packard, 4155B) and a luminance meter (Topcon, BM-3). The emission and absorption spectra were measured using a fiber 
optic spectrometer (Ocean Optics, S2000) and a spectrophotometer (Hitachi, U-1900), respectively.

\section{Results and discussion}

Figure 3 shows emission photographs (Fig. 3a) and EL spectra at $100 \mathrm{~mA} / \mathrm{cm}^{2}$ (Fig. 3b) for the PLEDs. For the single PLEDs, green and red emissions were observed for PFMEH-PPV and RP-145, respectively, where the green emission peaks occurred at 510 and $550 \mathrm{~nm}$, while the red at $650 \mathrm{~nm}$. The tandem PLED showed an orange emission color, which had three peaks at 510, 550, and $650 \mathrm{~nm}$, thus the emission color of the tandem PLED is the result of mixed emissions of the constituent single PLEDs. The conditions for the emission spectra measurement integration time and average were the same. Both the tandem and the single device emission spectra emission wavelengths and intensities agreed well, confirming that the orange emission corresponded with additive color mixing between the two single PLEDs. The lamination process enabled the formation of a tandem PLED based on general PLEDs with an extremely simple

(a)

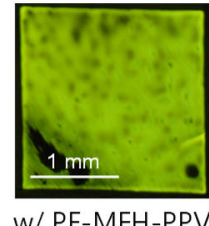

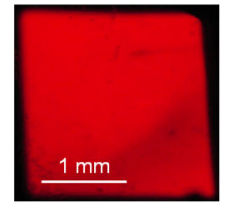

W/ RP145

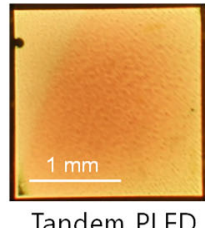

andem PLED
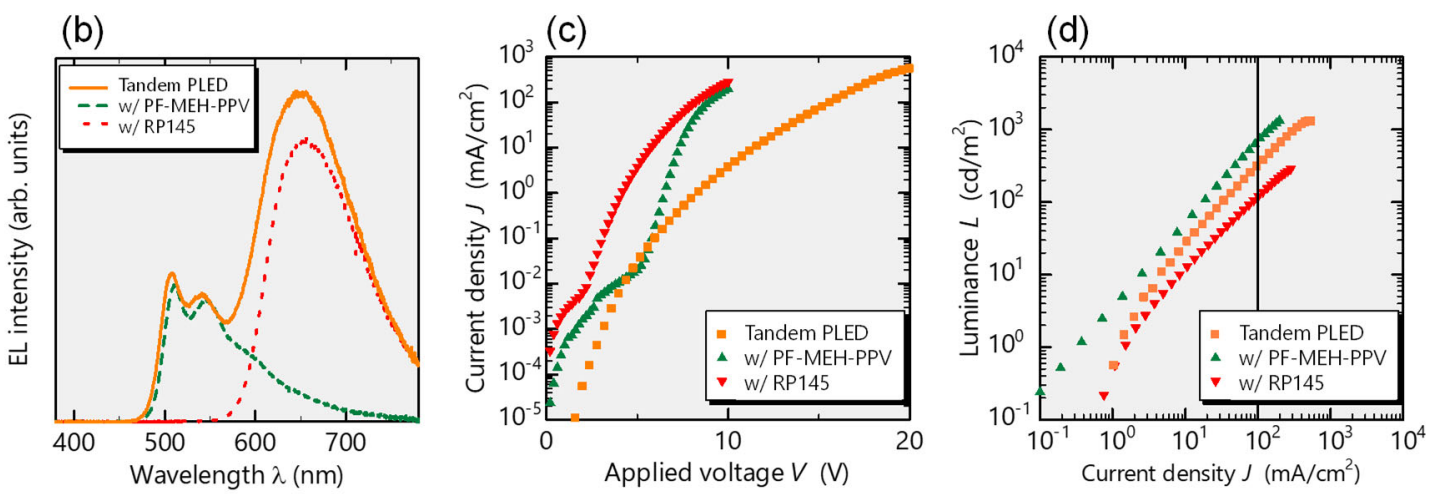

Figure 3. (a) Emission photographs, (b) emission spectra at $100 \mathrm{~mA} / \mathrm{cm}^{2}$, (c) $J-V$ curves, and (d) $L-J$ curves of single PLEDs with PF-MEH-PPV and RP145, and tandem PLED. 
process. Figure $3 \mathrm{c}$ shows the $J-V$ curves of the PLED devices. The applied voltage at $100 \mathrm{~mA} / \mathrm{cm}^{2}$ was estimated to be $9.8 \mathrm{~V}$ for the PF-MEH-PPV single PLED with a similar value of $8.2 \mathrm{~V}$ for the RP145 single PLED; however, a high voltage of $15 \mathrm{~V}$ at $100 \mathrm{~mA} / \mathrm{cm}^{2}$ was observed for the tandem PLED. This is because the thickness of the tandem PLED is twice that of the single PLEDs; thus, the drive voltage showed a large value in the tandem PLED. The increased device thickness resulted in a low leakage current at under $2 \mathrm{~V}$. Figure $3 \mathrm{~d}$ shows the $L-J$ curves of the PLED devices. The luminance at $100 \mathrm{~mA} / \mathrm{cm}^{2}$ was measured to be $480 \mathrm{~cd} / \mathrm{m}^{2}$ for the PF-MEH-PPV single PLED, $120 \mathrm{~cd} / \mathrm{m}^{2}$ for the RP145 single PLED, and $310 \mathrm{~cd} / \mathrm{m}^{2}$ for the tandem PLED. The tandem PLED showed a similar luminance value to the single PLEDs. The emission spectrum of the RP145 single PLED was larger than that of the PF-MEH-PPV single PLED but the luminance was higher for PF-MEH-PPV than RP145 because of the color correction factor that is related to the sensitivity of the human eye. The vertical axis of the emission spectra (Fig. 3b) represents optical power (W). However, the luminance (Fig. 3d) depends on the color correction factor (cd) which outputs its maximum value at $555 \mathrm{~nm}$; therefore, the PF-MEH-PPV single PLED attained a larger luminance than the others PLEDs despite its weaker emission spectrum.

(a)

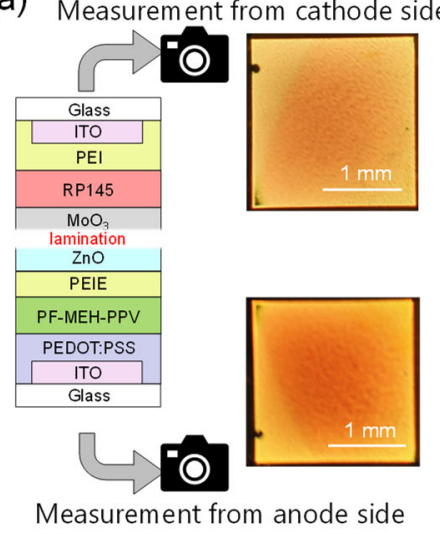

(b)

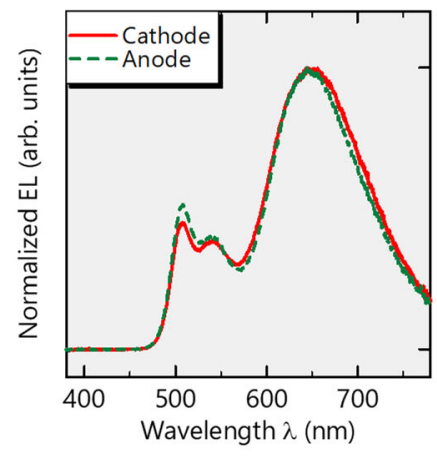

(c)

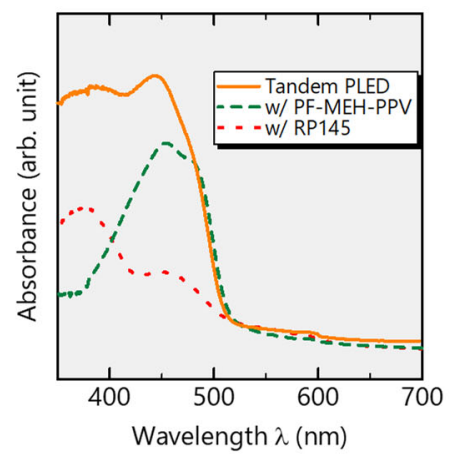

Figure 4. (a) Emission photograph from each ITO substrate and measurement schematics, (b) normalized emission spectra from each ITO substrate, and (c) absorption spectra of single and tandem PLEDs. 
The tandem PLEDs in this study had semi-transparent features because they did not use metal electrodes. Figure 4a shows emission photographs from the anode and cathode ITO substrates of the tandem PLEDs. The emission images appear to be similar to each other. Figure $4 \mathrm{~b}$ shows the normalized emission spectra. The total emission of the semi-transparent color mixing devices might be dominated by one substrate because of over-layer absorption of the under-layer emission. Thus, the total absorption spectra of the tandem devices required adjustment. The absorption spectra of the tandem and single PLEDs in this study are shown in Figure 4c. The absorption bands of all PLEDs were obtained at under $500 \mathrm{~nm}$. The tandem PLED emitted above $500 \mathrm{~nm}$ caused of PFMEH-PPV and RP145; therefore, the emission of the tandem PLED is not absorbed by the other layers. It is important to select a material so that the tandem PLEDs does not interfere with the emission wavelength.

\section{Conclusions}

We fabricated single and tandem type PLEDs using the wet and lamination processes. The under-layer in the tandem PLED was not dissolved by formation of the over-layers. The emission colors of the PF-MEH-PPV and RP145 single PLEDs were green and red, respectively, and that of the tandem PLED was orange, as a result of additive mixing of the colors of the stacked single PLEDs. The drive voltage of the tandem PLED increased compared to that of the single PLEDs because of the two-fold increase in thickness compared to that of a single PLED. The current-luminance conversion of the tandem PLED indicated a value similar to the single PLEDs. Additionally, the tandem PLED exhibited semi-transparency as shown in the photographs and emission photographs herein. To achieve a semi-transparent tandem PLED, material selection is important to ensure that the absorption and emission spectra of the tandem PLED are 
different.

\section{Acknowledgments}

This study was supported by a Charitable Trust of Ame Hisaharu Toyama Prefecture

University Research Grant Foundation, Kenjiro Takayanagi Foundation, and JSPS

KAKENHI Grant Number JP19K04465.

\section{Conflicts of interest}

The authors declare that they have no conflict of interest.

\section{References}

[1] Tang, C. W., VanSlyke, S. A., \& Chen, C. H. (1989). J. Appl. Phys. 65, 3610.

[2] Tang, C. W., \& VanSlyke, S. A. (1987). Appl. Phys. Lett. 51, 913.

[3] Fukagawa, H., Morii, K., Hasegawa, M., Arimoto, Y., Kamada, T., Shimizu T., \& Yamamoto, T. (2014). Appl. Phys. Express 7, 082104.

[4] Udagawa, K., Sasabe, H., Cai, C., \& Kido, J. (2014). Adv. Mater. 26, 5062.

[5] Uoyama, H., Goushi, K., Shizu, K., Nomura H., \& Adachi, C., (2014). Nature $492,234$.

[6] Kaji, H., Suzuki, H., Fukushima, T., Shizu, K., Suzuki, K., Kubo, S., Komino, T., Oiwa, H., Suzuki, F., Wakamiya, A., Murata, Y., \& Adachi, C. (2015). Nat. Commun. 6, 1.

[7] Nagata, R., Nakanotani, H., \& Adachi, C. (2017). Adv. Mater. 29, 1604265.

[8] Braun, D., \& Heeger, A. J. (1991). Appl. Phys. Lett. 58, 1982.

[9] White, M. S., Kaltenbrunner, M., Głowacki E. D., Gutnichenko, K., Kettlgruber, G., Graz, I., Aazou, S., Ulbricht, C., Egbe, D. A. M., Miron, M. C., Major, Z., Scharber, M. C., Sekitani, T., Someya, T., Bauer, S., \& Sariciftci, N. S. (2013). Nat. Photonics 7, 811.

[10] Höfle, S., Schienle, A., Bruns, M., Lemmer, U., \& Colsmann, A. (2014). Adv. Mater. 26, 2750.

[11] Parker, I. D. (1994). J. Appl. Phys. 75, 1656. 
[12] Han, D., Khan, Y., Ting, J., King, S. M., Yaacobi-Gross, N., Humphries, M. J., Newsome, C. J., \& Arias, A. C. (2017). Adv. Mater. 1606206, 1606206.

[13] Yokota, T., Zalar, P., Kaltenbrunner, M., Jinno, H., Matsuhisa, N., Kitanosako, H., Tachibana, Y., Yukita, W., Koizumi, M., \& Someya, T. (2016). Sci. Adv. 2, e1501856.

[14] Zhong, C., Duan, C., Huang, F., Wu, H., \& Cao, Y. (2011). Chem. Mater. 23, 326.

[15] Takayama, M., Naka, S., \& Okada, H. (2013). Jpn. J. Appl. Phys. 52, 05DC15.

[16] Kim, J. S., Ho, P. K. H., Murphy, C. E., \& Friend, R. H. (2004). Macromolecules $37,2861$.

[17] Guo, T. F., Pyo, S., Chang, S. C., \& Yang, Y. (2001). Adv. Funct. Mater. 11, 339.

[18] Miyagawa, M., Koike, R., Takahashi, M., Bessho, H., Hibino, S., Tsuchiya, I., Harano, M., Endo, M., \& Taniguchi, Y. (2007). Jpn. J. Appl. Phys. 46, 7483.

[19] Ohmori, M., Ueno, S., Kurachi, N., Sawamura, M., Hattori, M., Inoue, T., Miyabayashi, T., Takao, Y., Hibino, S., Tsuchiya, I., Bessho, H., Ohara, K., Ohama, M., Hoshino, M., Ayukawa, S., Miyasato, R., Tsutsui, N., Miura, N., Yamanaka, M., Naka, S., Shibata, M., \& Okada, H. (2008). Jpn. J. Appl. Phys. 47,472 .

[20] Shoda, K., Morimoto, M., Naka, S., \& Okada, H. (2019). IEICE Trans. Electron. E102.C, 196.

[21] Minani, T., Satoh, R., Okada, H., \& Naka, S. (2011). Jpn. J. Appl. Phys. 50, $01 \mathrm{BC} 12$.

[22] Matsumoto, T., Nakada, T., Endo, J., , N. Mori, K., Kawamura, Yokoi, A., \& Kido, J. (2003). SID Symp. Dig. Tech. Pap. 34, 979.

[23] Pu, Y. J., Chiba, T., Aizawa, N., Sasabe, H., \& Kido, J. (2013). J. Photopolym. Sci. Technol. 26, 403. 
